\title{
The Mechanical and Fracturing of Rockburst in Tunnel and Its Acoustic Emission Characteristics
}

\author{
Xiangxin Liu $\mathbb{D},{ }^{1}$ Sibo Zhan, ${ }^{1}$ Yanbo Zhang $\mathbb{D},{ }^{1}$ Xiaolei Wang, \\ Zhengzhao Liang, ${ }^{2}$ and Baozhu Tian ${ }^{1}$ \\ ${ }^{1}$ School of Mining Engineering, North China University of Science and Technology, Tangshan, Hebei 063210, China \\ ${ }^{2}$ State Key Laboratory of Coastal and Offshore Engineering, Dalian University of Technology, Dalian, Liaoning 116024, China
}

Correspondence should be addressed to Yanbo Zhang; fzdn44444@163.com

Received 5 January 2018; Accepted 13 March 2018; Published 5 June 2018

Academic Editor: Longjun Dong

Copyright (C) 2018 Xiangxin Liu et al. This is an open access article distributed under the Creative Commons Attribution License, which permits unrestricted use, distribution, and reproduction in any medium, provided the original work is properly cited.

\begin{abstract}
The phenomenon of acoustic emission (AE) is associated with rock failure and rock fracturing. In order to investigate the influence of tectonic stress on rockburst in tunnel, a biaxial loading experiment system was used in this study. The excavation operation is undertaken at the center of samples to monitor the tunnel forming process in situ, and the different horizontal stresses can be studied by using the AE monitoring technique. The dynamical fracturing process of the tunnel model was summarized, and the timing parameters of AE signals in rockburst stages were obtained. The curves of AE energy and cumulative AE energy with time show a "step-like" rising trend before the occurrence of rockburst. The evolution of macro- and mesocracks is captured, and the mechanical conditions for a "V-shaped" rockburst pit are derived. As the horizontal stress increases, the effect of excavation unloading becomes more pronounced, and the damage caused by the rockburst intensifies. In the early stage of rockburst evolution, the fracturing type follows a model of tensile-shear mix model. A positive relationship between the ratio of shear fracturing type and the horizontal stress can be noted when the rock is about to burst, and the high intensity and the high energy released of from the rock-fracturing event have become evident. Thus, the results indicate that one should focus on monitoring both sides of the surrounding rock of the tunnel so as to extract the characteristics of the process of tunnel in tunnel. The applications of biaxial loading system and during an excavation operation provide a useful tool to simulate the rock burst in tunnel at an engineering site.
\end{abstract}

\section{Introduction}

The rockburst is a class of rock failure where strain energy is suddenly released by an unstable fracture of rock [1-4]. Typically occurring in deep underground mines, rockburst is a common disaster. The opening of a tunnel relieves neighboring rocks of tremendous pressure, which can literally cause the rock to explode as it attempts to reestablish stress and strain equilibrium [5]. The released energy leads to a violent fracture of the surrounding rock around the excavation and reduces the potential energy of the rock, which makes the surrounding rock reach another equilibrium state [6].

In the past few years, many methods of forecasting rockbursts have been proposed, including the assessment of rock, stress and strain detection, and modern mathematical theories. However, a comprehensive understanding of rock bursts and associated damage mechanisms has remained elusive $[7,8]$. Based on the agitated behavior of animals prior to earthquakes, a semiquantitative study has been carried out on the possibility of the emission of acoustic strain and fracture radiation prior to such events. Such emission has been observed in the laboratory and in mines and is termed as an acoustic emission (AE) phenomenon [9]. The AE phenomenon is defined as elastic mechanical waves associated with a rapid release of localized stress energy propagated within the material. AE monitoring is a useful tool for studying rock fracturing $[10,11]$. In order to understand the physical process generating seismicity within volcanic edifices, some studies have been based on monitoring an array of transducers around a rock sample, permitting the full-waveform capture, location, and analysis of microseismic events $[12,13]$. In order to distinguish between the seismic events and blasts generate seismic waveforms, several characteristic parameters were extracted as discriminant indicators. 

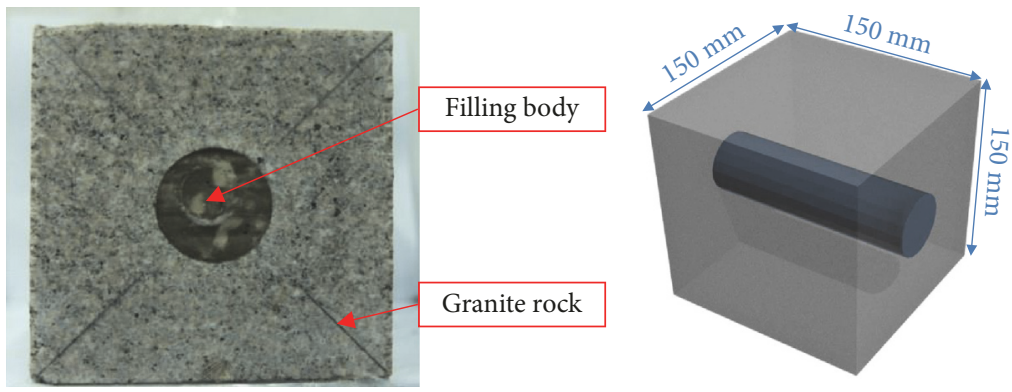

FIgURE 1: Tunnel model.

Fisher classifier, naive Bayesian classifier, and logistic regression were used to establish discriminators between them. Research result showed a reasonably good discriminating performance $[14,15]$. In order to solve the accuracy of localization methods based on the arrival time difference, the collaborative localization method using analytical and iterative solutions (CLMAI) was proposed, which combined with the arrivals of multisensor and inversion of the real-time average wave velocity, to seek the optimal locating results. This method has the following four advantages: without iterative algorithm, without premeasured velocity, without initial value, and without square root operations $[16,17]$. In in situ direct shear test studies, an initially intact region of rock bounded by joints and a seam are fractured, generating an AE. Large-scale inhomogeneous rock-fracturing experiments, such as the in situ direct shear tests, may provide useful insights as analog models of seismogenic faulting [18]. The rockburst proneness index and the AE energy rise as the temperature increases. That is, the degree of rockburst increases rather than decreases with rising temperature, and this is helpful for explaining rockburst disasters in tunnels at high ground temperature [19]. A true-triaxial unloading testing machine was utilized to perform rockburst tests on granite specimens with changing heights for size effect investigations. A size effect exists during a rockburst simulation process and affects the rock failure strength and fracture mode [20-22]. Because of high stiffness and strength in high stress conditions, a rockburst in brittle fracturing can produce intensive $\mathrm{AE}$ activity and large amounts of energy. It is appropriate to locate the failure positions and determine the energy released in rock fracturing by using the AE technique [23-25]. In order to investigate the distribution regularity of microseismic events released by the coal mining, the microseismic monitoring technique is used to monitor induced roof rock mass along the vertical and horizontal directions. A method is developed to determine the displacement angle using the microseismic monitoring data [26].

It is generally accepted that a rockburst is dependent on the size and depth of the excavations, and we also know that the likelihood of rockbursts occurring increases as depth increases. In this study, rockburst in tunnel was monitored on granite rocks using the $\mathrm{AE}$ monitoring system, and different horizontal stresses were considered. The characteristics of AE signals were analyzed to predict the occurrence rockburst.

\section{Rockburst in Tunnel Experiments}

2.1. Sample Preparation. Granite rocks were chosen as the samples in this experiment, and the size of rock samples was set at $150 \mathrm{~mm} \times 150 \mathrm{~mm} \times 150 \mathrm{~mm}$. The specimen indexes were prepared in accordance with the Standard for Test Method of Engineering Rock Mass (GB/T50266-99).

As shown in Figure 1, to simulate the tunnel model, a hole of $\Phi=45 \mathrm{~mm}$ was set in front and rear center of the rock sample, and the parallelism error of two head faces was within $0.02 \mathrm{~mm}$. The filling body is filled up around the hole, and the filling body is made by the quartz sand and the special expansion cement at the mixture ratio of $1: 1$.

2.2. Laboratory Equipment. The experimental system is comprised a loading system and an AE system (Figure 2).

(i) Loading system (RLW-3000): the servo-controlled rock-testing machine is produced by Chaoyang Test Instrument Corporation, China. The deformation and applied vertical force can be monitored. The capacity of the axial load transducer is up to $3000 \mathrm{kN}$, and the capacity in the horizontal direction is up to $1000 \mathrm{kN}$.

(ii) AE monitoring system (PCI-2): the AE monitoring system is produced by Physical Acoustics Corporation in the US. The AE activities of rock fracturing were recorded by an $\mathrm{AE}$ detector with eight channels. The multiparameter AE data, including waveform, hits, ring-down counts, and amplitudes, are obtained using the AE system.

In addition, the air conditioner, which is used to guarantee a constant temperature in the laboratory, is produced by Gree Company, China.

In order to guarantee the conformity of the experimental data, the equipment setup should be kept consistent [28]. The AE devices were set as follows: the sampling time was set at $0.2 \mu \mathrm{s}$, and the memory length was set at $2 \mathrm{k}$ (i.e., 2048 words). In this case, the recording time was approximately $0.4 \mathrm{~ms}$ $(0.2 \mu \mathrm{s} \times 2048)$. The pretrigger was set at $1 \mathrm{k}$; the sampling rate was set at $1 \mathrm{MHz}$.

2.3. Loading Condition. In general, the underground rock is mainly affected by vertical stress and horizontal stress, both 


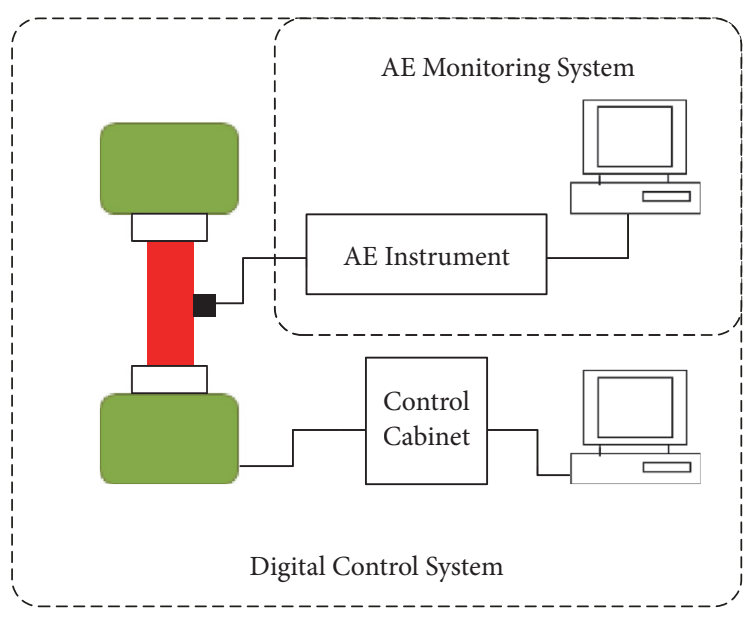

(a)

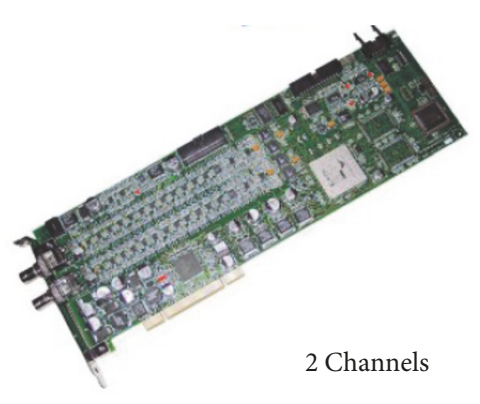

(d)

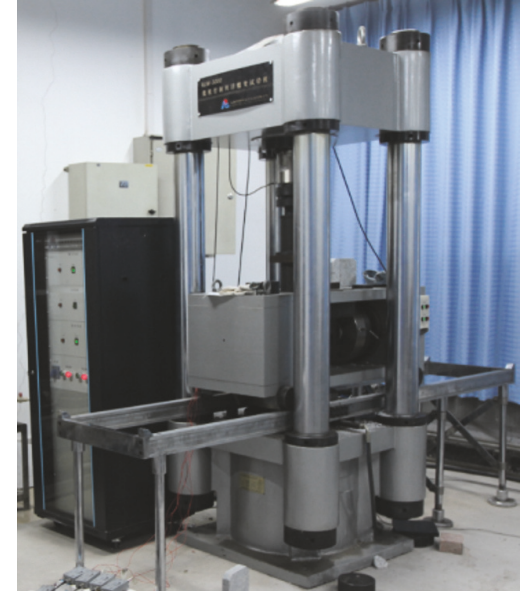

(b)

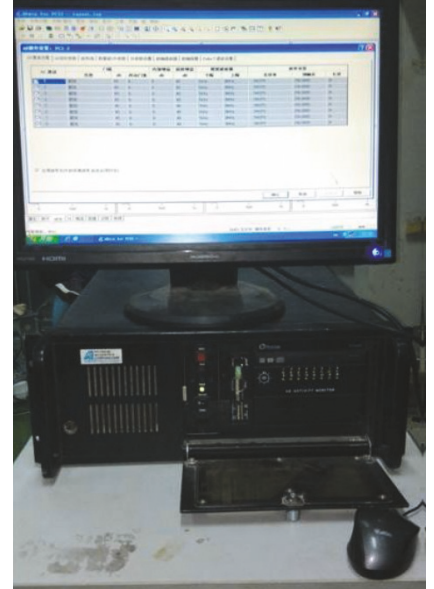

(c)

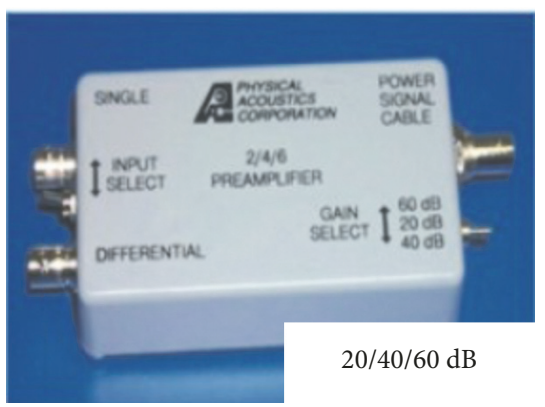

(e)

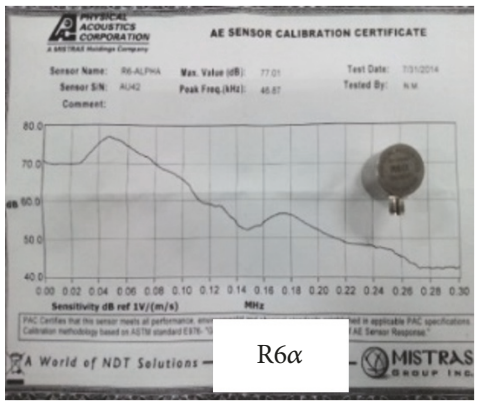

(f)

FIGURE 2: The experimental setup ((a) the experimental system; (b) the RLW-3000 biaxial loading system; (c) acoustic emission monitoring system of PCI-2; (d) acquisition card; (e) preamplifier; (f) sensor).

of which form the initial stress field [29]. The vertical stress is affected by depth and upper overburden; the horizontal stress (also called the tectonic stress) is affected by diagenesis and tectonic movement. Thus, in this experiment, the biaxial servo experimental testing machine is used, which applies pressure both horizontally and axially.

The operating steps of the biaxial servo experimental testing machine are as follows (Figure 3):

(1) The first step is to preload $20 \mathrm{kN}$ horizontally and axially before the experiment officially starts.

(2) Both directions are loaded at a rate of $1000 \mathrm{~N} / \mathrm{s}$. The horizontal directions are loaded to $100 \mathrm{kN}, 200 \mathrm{kN}$, and $300 \mathrm{kN}$, respectively, and the axial directions are loaded to $800 \mathrm{kN}$.

(3) After the mechanical state completion (where the horizontal force is $100 \mathrm{kN}$, or $200 \mathrm{kN}$, or $300 \mathrm{kN}$, and the axial force is $800 \mathrm{kN}$ ), the force boundary condition is maintained for $5 \mathrm{~min}$.

(4) The filling body is detached by the extrusion device, and the current stress state is maintained for another $5 \mathrm{~min}$ to the stress adjustment.

(5) Finally, the tunnel model is loaded in the vertical direction at a rate of $0.3 \mathrm{~mm} / \mathrm{min}$ until the rockburst appears around the tunnel wall.

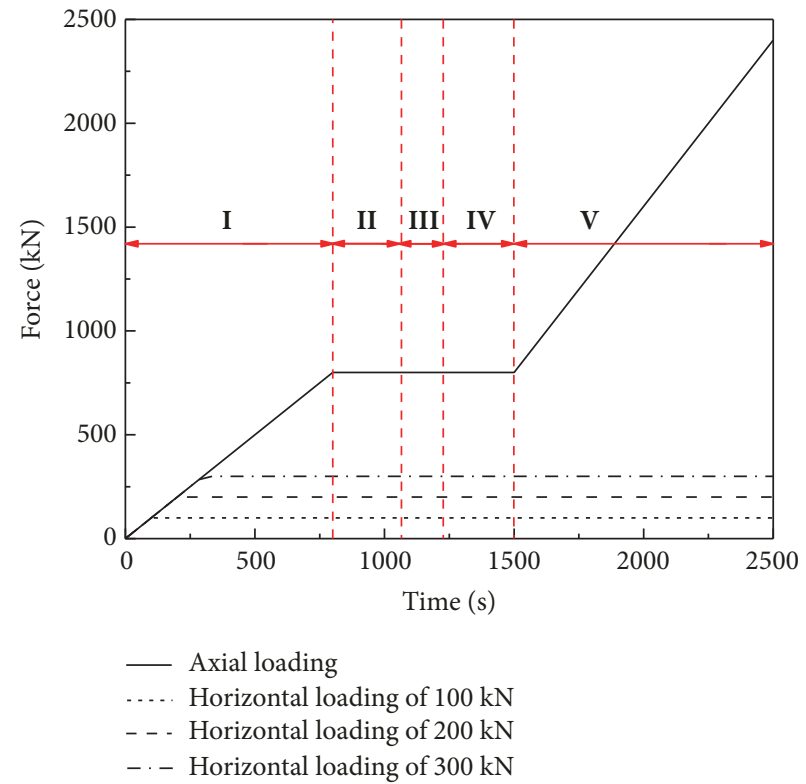

FIGURE 3: Loading process (I: initial loading; II: maintaining the loading number in two directions; III: detaching the filling body; IV: maintaining the loading number in two directions; $\mathrm{V}$ : loading in the vertical direction again). 


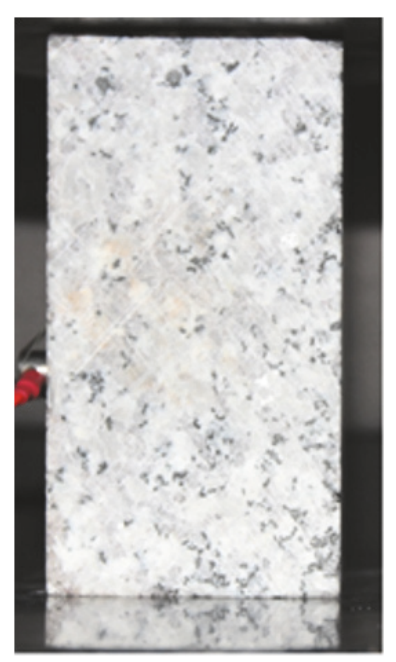

(a) Granite sample

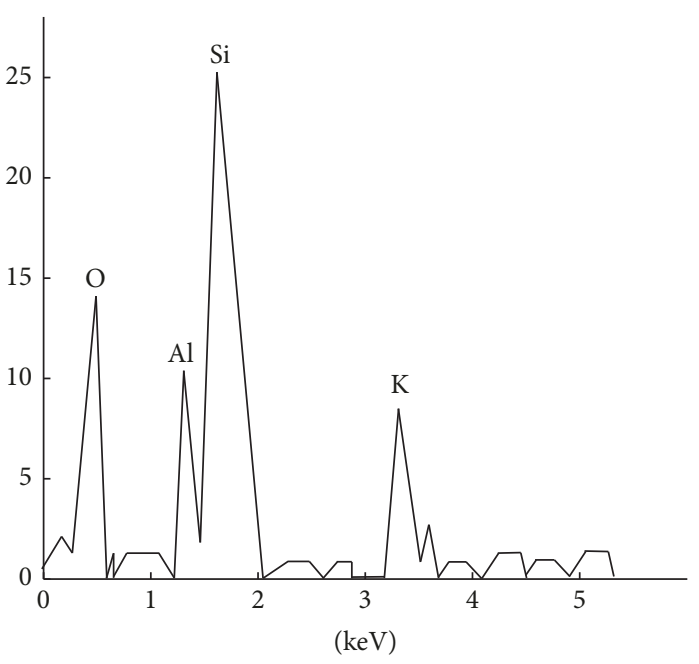

(b) X-ray diffraction results

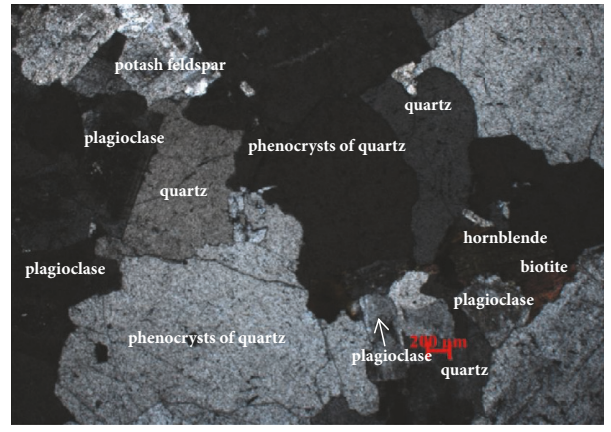

(c) Image from the result of polarizing microscope

FIgURE 4: Rock composition.

\section{Experimental Results}

\subsection{Rockburst Tendency}

3.1.1. Mineral Composition Analysis. A number of engineering cases show that rockbursts often take place at rock masses that have hard texture, good brittleness, and elasticity [30]. Granite rock has a high modulus of elasticity. This study uses granite rock from Laizhou in China. Rockburst often occurs in the deep mines located around this area.

The granite samples were observed under a polarizing microscope by transmitted light, as well as detected by X-ray diffraction. The results are shown in Figure 4. The dominant components of the granite samples are plagioclase, potash feldspar, quartz, hornblende, and biotite. The specific mineral form and its components are accounted for as follows. The flaggy plagioclase content is approximately $35-40 \%$, and it has albite twins and a circle-type structure, obviously kaolinization and sericitization. The flaggy potash feldspar content is approximately $25-30 \%$ and shows different degrees of kaolinization and sericitization. The granular quartz content is approximately $20-25 \%$. The columns hornblende content is approximately $3-5 \%$, also showing chloritization. Some other minerals, such as biotite, titanite, monazite, and magnetite, also appear, their contents being approximately $2-3 \%$.

3.1.2. Analysis of Rockburst Tendency. One of the necessary conditions for rockburst to occur is that the rock should have the capacity for a large amount of elastic energy storage [31]. Thus, we selected the Energy Criterion to calculate the rockburst tendency of granite rock. The Energy Criterion can be expressed as follows:

$$
U=\frac{\sigma_{c}^{2}}{2 E},
$$

where $\sigma_{c}$ is the uniaxial compressive strength; and $E$ is the elastic modulus.
When $U$ is larger, the ability of energy storage of rock is higher, so that the rockburst tendency is greater. Based on these results, we can divide the rockburst tendency into four levels: (1) Grade I, the weak rockburst, $U<40 \mathrm{~kJ} / \mathrm{m}^{3}$; (2) Grade II, the medium rockburst, $40 \mathrm{~kJ} / \mathrm{m}^{3}<U \leq$ $100 \mathrm{~kJ} / \mathrm{m}^{3}$; (3) Grade III, the strong rockburst, $100 \mathrm{~kJ} / \mathrm{m}^{3}<$ $U \leq 200 \mathrm{~kJ} / \mathrm{m}^{3}$; and (4) Grade IV, the strongest rockburst, $U \geq 200 \mathrm{~kJ} / \mathrm{m}^{3}$.

The mechanical parameters of granite rock can be seen in Table 1. Based on the experimental results, the rockburst tendency of the granite samples is 74.63-94.03; it is Grade II, corresponding to medium rockburst.

3.2. Destruction Phenomenon of Rockburst in Tunnel on the Macroscale. Along with the rockburst evolution, the evolution of rockburst in tunnel can be divided into four stages $[20,32]$, the quiet period stage, the particle ejection stage, the flaking and particle ejection stage, and the complete ejection stage. In this research, the evolution of rockburst in tunnel can be seen in Figure 5. There is no significant significance with regard to the early loading (Figure 5(a)). An increase of loading results in small particles of rock appearing up along the tunnel model (Figure 5(b)), and then the particles become larger (Figure 5(c)). Thereafter, misty rock powder can be observed in the tunnel model (Figures 5(d) and 5(e)). As the loading continues to increase, a rockburst occurs and many rockburst pits can be found at approximately waist height in the surrounding rock in the tunnel.

The relationship between the horizontal force and the rockburst fracturing characteristics is seen in Table 2 .

3.3. Relationship between Horizontal Stress and Rockburst Intensity in a Tunnel. The rockburst intensity in a tunnel can be described by the morphological characteristics of the burst surface, the depth and width of fracturing, and the acoustic features [33]. The final fracturing morphology of different horizontal stresses can be seen in Figure 6. 
TABLE 1: Rockburst proneness of granite samples.

\begin{tabular}{lcccc}
\hline No. & $\begin{array}{c}\text { Elastic Modulus } \\
(\mathrm{GPa})\end{array}$ & $\begin{array}{c}\text { Uniaxial compressive } \\
\text { strength }(\mathrm{MPa})\end{array}$ & $\begin{array}{c}\text { Energy criterion } \\
\left(\mathrm{kJ} / \mathrm{m}^{3}\right)\end{array}$ & Level of rockburst tendency \\
\hline HGY-1 & 61.1 & 72.8 & 74.63 & II \\
HGY-2 & 51.8 & 83.6 & 94.03 & II \\
HGY-3 & 56.2 & 75.8 & 93.84 & II \\
\hline
\end{tabular}

TABLE 2: Experimental results of a rockburst in tunnel.

\begin{tabular}{|c|c|c|}
\hline $\begin{array}{l}\text { Horizontal } \\
\text { force }(\mathrm{kN})\end{array}$ & $\begin{array}{l}\text { Peak force of axially } \\
\text { direction }(\mathrm{kN})\end{array}$ & Fracturing characteristics during rockburst evolution \\
\hline 100 & 2223 & $\begin{array}{l}\text { When the axial loading reaches } 1927 \mathrm{kN} \text {, the rock granules catapult from the surrounding rock, and } \\
\text { then flake peeling occurs in the surrounding rock. When the axial loading reaches } 2128 \mathrm{kN} \text {, "V-shaped" } \\
\text { rock burst pits appear. }\end{array}$ \\
\hline 200 & 2492 & $\begin{array}{l}\text { When the axial loading reaches } 2127 \mathrm{kN} \text {, the rock granules catapult from the surrounding rock, then } \\
\text { flake peeling appears with a small amount of rock dust discharged as a mist. When the axial loading } \\
\text { reaches } 2437 \mathrm{kN} \text {, "V-shaped" rock burst pits appear. }\end{array}$ \\
\hline 300 & 2423 & $\begin{array}{l}\text { When the axially loading reaches } 1754 \mathrm{kN} \text {, the rock granules and flake peeling catapult from the } \\
\text { surrounding rock. When the axially loading reaches } 2400 \mathrm{kN} \text {, "V-shaped" rock burst pits appear. }\end{array}$ \\
\hline
\end{tabular}

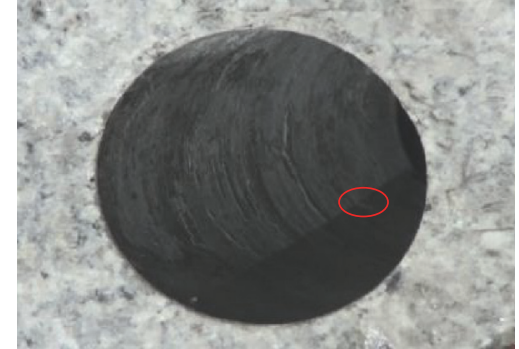

(a) $669 \mathrm{~s}$

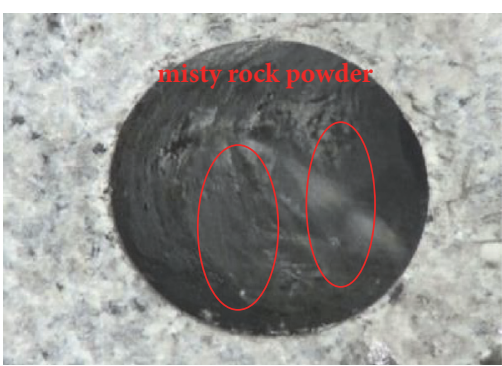

(d) $1042 \mathrm{~s}$

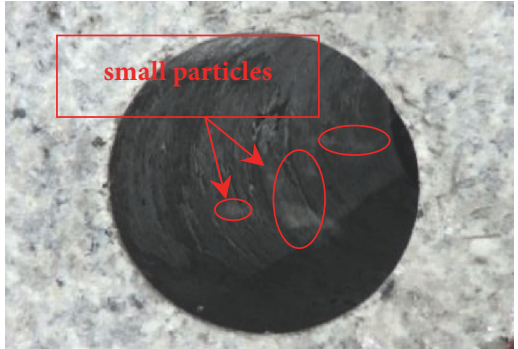

(b) $889 \mathrm{~s}$

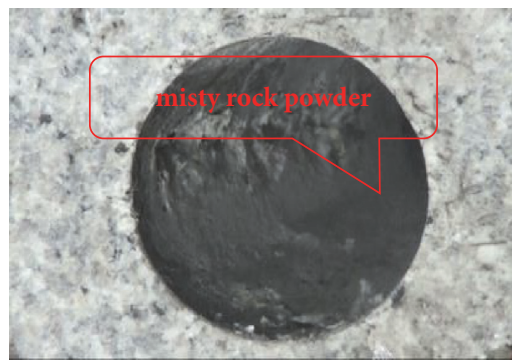

(e) $1054 \mathrm{~s}$

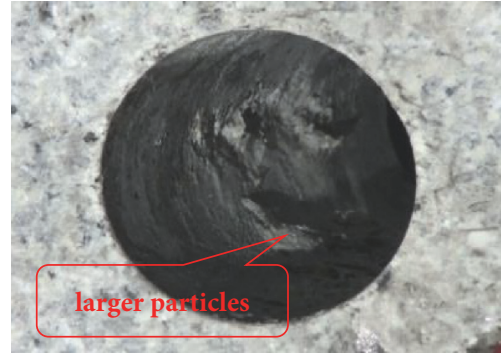

(c) $1001 \mathrm{~s}$

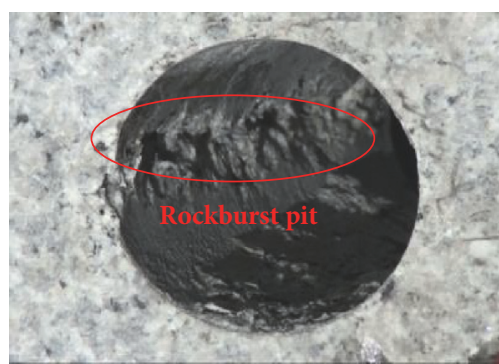

(f) $1100 \mathrm{~s}$

FIgURE 5: Process of rockburst in tunnel.

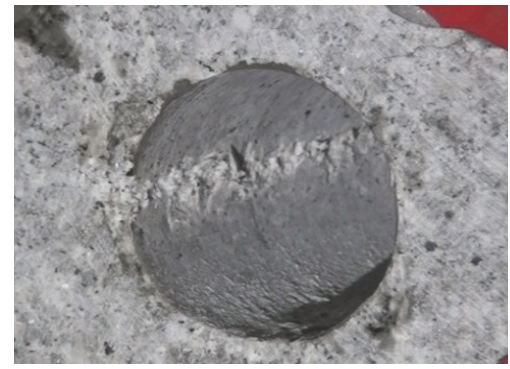

(a) Horizontal stress is $100 \mathrm{kN}$

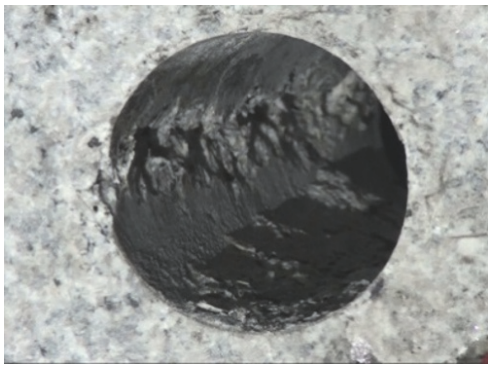

(b) Horizontal stress is $200 \mathrm{kN}$

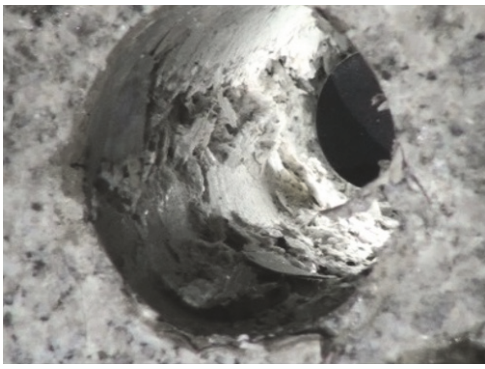

(c) Horizontal stress is $300 \mathrm{kN}$

FIGURE 6: Final fracturing morphology of rockburst in tunnel under different horizontal stresses. 

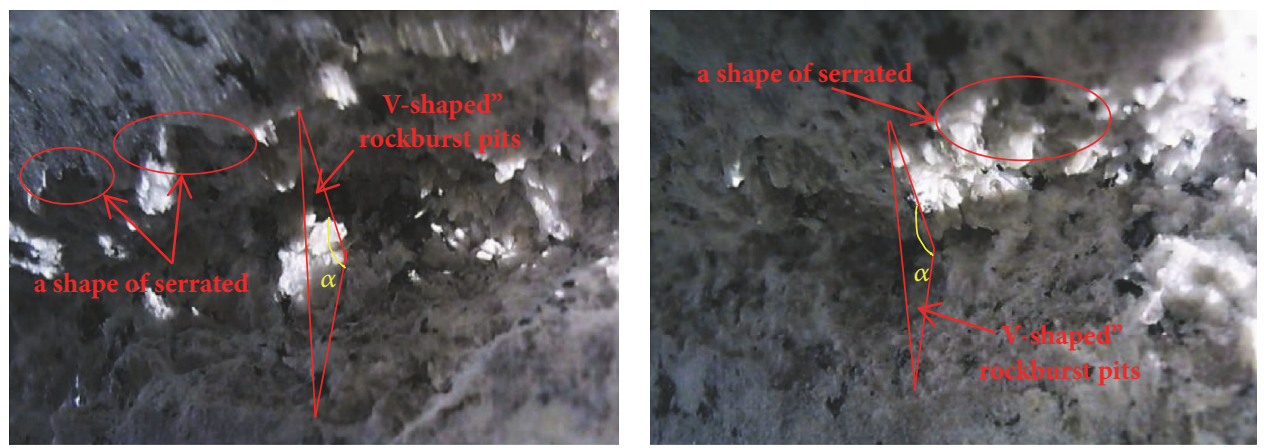

FIGURE 7: Macroscopic morphology of a rockburst.

During the same time, there is a positive correlation between the horizontal stress and the accumulation of strain energy [34]. The horizontal stress has a close influence on the final fracturing morphology of rockburst in tunnel, such as (1) when the horizontal stress is $100 \mathrm{kN}$ (Figure 6(a)), the intensity of rockburst in tunnel is the lowest; (2) when the horizontal stress is $200 \mathrm{kN}$ (Figure 6(b)), the intensity of rockburst in tunnel is greater than $100 \mathrm{kN}$ (the bottom of the tunnel has several rock fragments, and the both sides of the tunnel have a cratering shape from the rockburst); and (3) while the horizontal stress is $300 \mathrm{kN}$ (Figure 6(c)), the rockburst intensity causes the most serious damage and forms a clear "V-shape" of continuous rockburst pits along both sides of the tunnel.

3.4. Macroscopic Morphology of Rockbursts. In underground mines, the elastic strain energy release of rocks is accompanied by the formation of new free surfaces during the rock fragmentation by blasting and is a transient process [35]. In the different areas of surrounding rock of a tunnel, the tensile- and shear-crack can be found from time- and spacescales. For this problem of a rockburst in tunnel, the following process occurs: split (tension stress) into a plate $\rightarrow$ shear (shearing stress) into a column.

From Figure 7, we can analyze the geometric features of rockburst. The overall fracturing surface of a rockburst is seen to have a "V-shape". The edge of the fracturing surface is seen to have serrated shape. Both sides of the rockburst pits are seen to have a stepped shape.

\section{Analysis of AE Characteristics of Rockburst in Tunnel}

4.1. Influence of AE Characteristics under Different Horizontal Stresses. The phases of the evolutionary process of AE energy characterize the energy evolution during a rockburst process (Figure 8). Based on the pattern of the axis loading curve, the schematic change of AE timing parameters (energy and cumulate energy) can be divided into four stages.

(I) The stage of pregnant rockburst: the amount of $\mathrm{AE}$ energy and cumulative AE energy is at a very low level. Some random fracturing occurs.

(II) The stage of small particle ejection: the curves of $\mathrm{AE}$ energy and cumulative AE energy have a slight upward trend, so that the strength of fracturing is greater.
TABLE 3: Accumulation AE energy and precursor time for different horizontal stress.

\begin{tabular}{lcc}
\hline $\begin{array}{l}\text { Horizontal } \\
\text { stress } \\
(\mathrm{kN})\end{array}$ & $\begin{array}{c}\text { Accumulation AE energy } \\
(\mathrm{E} 10 \times \mathrm{aJ})\end{array}$ & $\begin{array}{c}\text { Relative time of } \\
\text { precursor }\end{array}$ \\
\hline 100 & 4.82 & 0.90 \\
200 & 6.56 & 0.89 \\
300 & 9.39 & 0.86 \\
\hline
\end{tabular}

(III) The stage of flake peeling: the AE energy curve displays several obvious surge events, and the cumulative $\mathrm{AE}$ energy curve displays a phenomenon of "step-like" rising. Some rock burst events with high intensity appear.

(IV) The stage of rockburst occurrence: the AE energy curve starts to display the phenomenon of a sudden increase in frequently, and the cumulative $\mathrm{AE}$ energy curve is in a rising state. The high intensity and high energy release of rock fracturing appears in this.

The amount of cumulative AE energy refers to the energy release during rock burst evolution. From the amount of energy released during rockburst evolution, the time of rockburst occurrence and precursor time for different horizontal stresses also have some variances (Table 3). The relationship between horizontal stress and amount of energy release is positively correlated and is the same as the horizontal stress and degree of intensity of a rockburst. By different conditions of horizontal stress, the cumulative AE energy curve displays "step-like" inflection points before the rockburst occurs (Figure 8).

4.2. Analysis of the Rockburst Fracturing Model. The original stress of the surrounding rock of a tunnel will cause redistribution because of the unloading excavation [36]. It forms a disturbance stress distribution, and the disturbance stress is in an unstable state. Research shows that the relationship between RA and AF reflects the crack mode during rock fracturing $[37,38]$, where

$$
\begin{aligned}
& \mathrm{RA}=\frac{\text { Rise Time }}{\text { Amplitude }} \\
& \mathrm{AF}=\frac{\text { Counts }}{\text { Duration Time }} .
\end{aligned}
$$




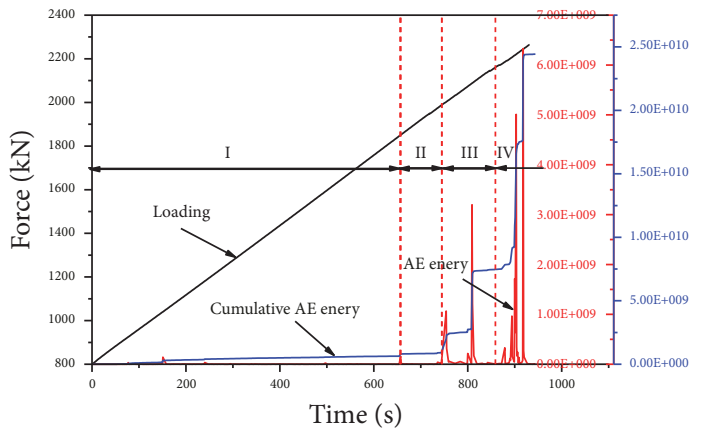

(a) Horizontal stress of $100 \mathrm{kN}$

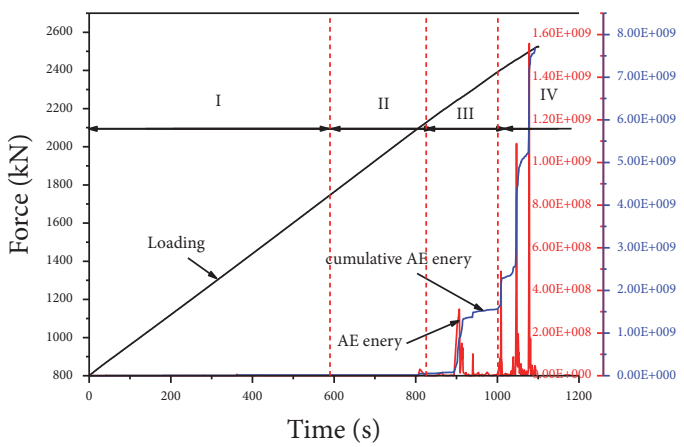

(b) Horizontal stress of $200 \mathrm{kN}$

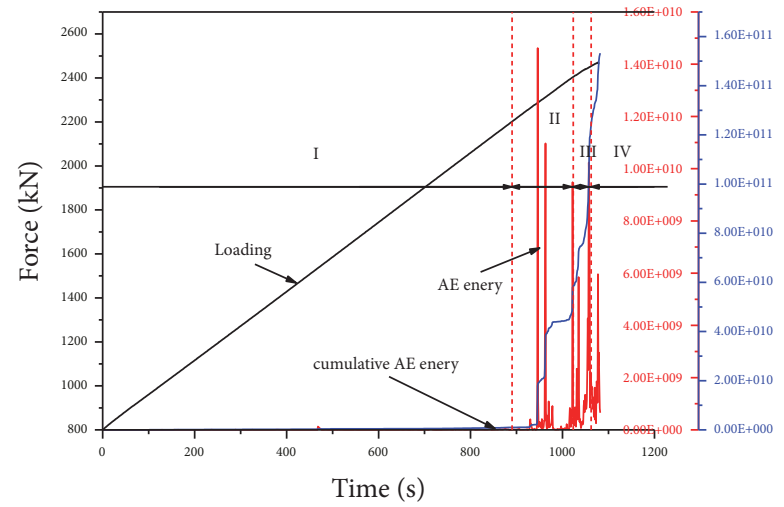

(c) Horizontal stress of $300 \mathrm{kN}$

FIGURE 8: Loading curves and AE parameters; (I: pregnant rockburst stage; II: small particle ejection stage; III: flake peeling stage; IV: rockburst occurrence stage).

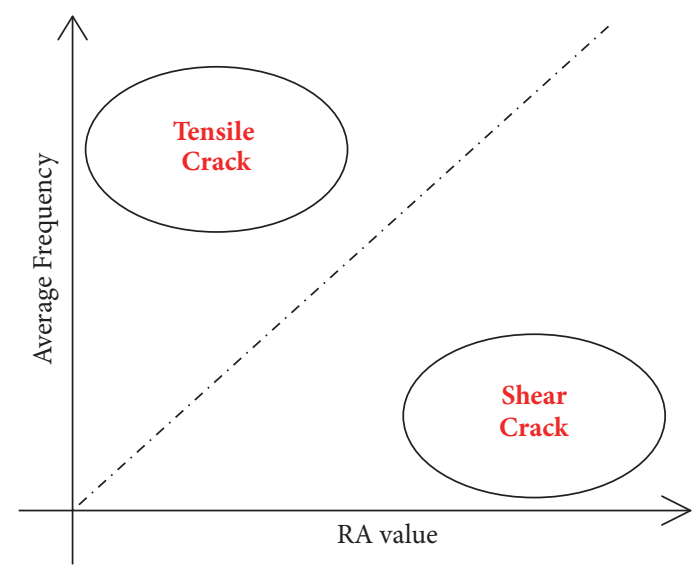

Figure 9: Conventional crack classification [27].

This type of cracking can be classified by the following factors [27]: (1) Mode I, tensile crack, has a high AF value and a low RA value; (2) Mode II, shear movement, has a low AF value and a high RA value (Figure 9).

By analysis of the rockburst evolution, the process can be divided as follows: the stage of quiet period $\rightarrow$ the stage of particle ejection $\rightarrow$ the stage of flaking and particle ejection $\rightarrow$ the stage of complete ejection. From the view of crack analysis, the process of " $\mathrm{V}$ " formation can be divided as follows: "split (tension stress) into a plate $\rightarrow$ shear (shear stress) into a column $\rightarrow$ fly out". As shown in Figure 10, the crack distribution during rockburst evolution reflects and characterizes the effect of horizontal stress as follows.

(1) In general, there is a common feature in the three types of horizontal stress. The main fracturing mode is tensile in the quiet period stage, which matches the process of split (tension stress) into a plate. In the complete ejection stage, the fracturing mode switches to shear (shear stress) into a column.

(2) There are also some personality characteristics between the three types of horizontal stress. When the horizontal stress is $100 \mathrm{kN}$, the fracturing mode from the quiet period stage to the flaking and particle ejection stage is tensile fracturing; shear fracturing appears in the final stage. When the horizontal stress is $200 \mathrm{kN}$, the fracturing mode in the particle ejection stage begins to appear as shear fracturing. When the horizontal stress is $300 \mathrm{kN}$, the quiet period stage and the particle ejection stage are a mixed mode of tensile- and shear fracturing but displays a state of pure shear fracturing in the stage of flaking and particle ejection and the complete ejection stage.

The results are consistent with the relationship between the stress boundary conditions and the characteristics of rockburst occurrence. Thus, as the horizontal stress increases, the fracturing type in the early stage is displayed as a 

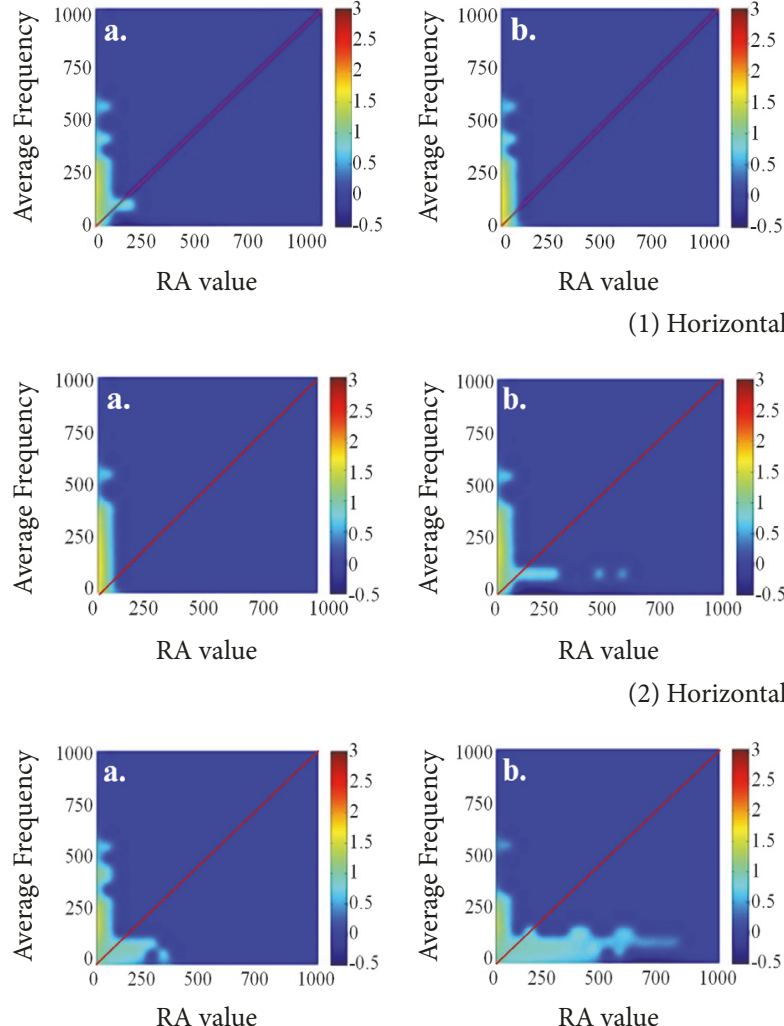

RA value

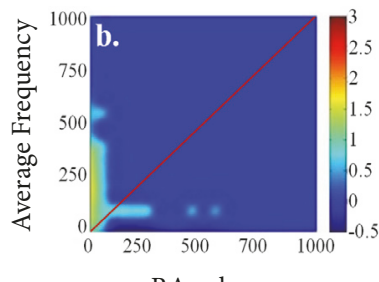

(2) Horizontal stress of $200 \mathrm{kN}$

(3) Horizontal stress of $300 \mathrm{kN}$
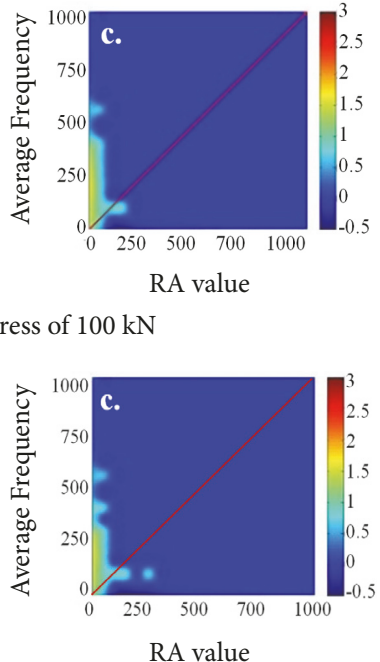

RA value

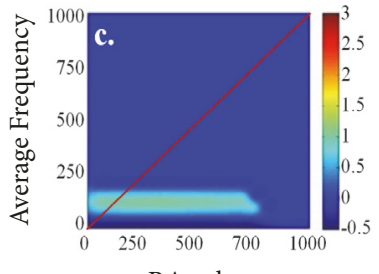

RA value
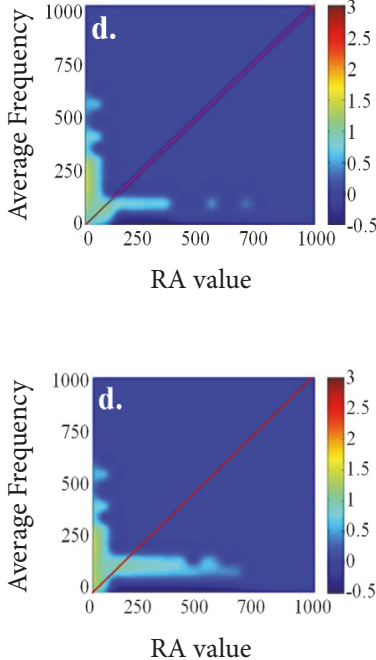

RA value

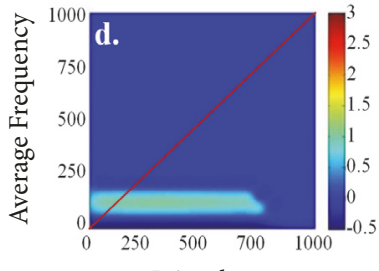

RA value

FIGURE 10: Distribution patterns in the rockburst evolution process under different confining pressures; ((a) the quiet period stage; (b) the particle ejection stage; (c) the flaking and particle ejection stage; (d) the complete ejection stage).

mixed mode of tensile- and shear fracturing; pure shear fracturing occurs at a later stage. The strength of rockburst occurrence is positively correlated with the horizontal stress.

\section{Discussion}

5.1. Derivation of Tunneling Model Excavation Mechanics. This is supported by the excavation operation in the experimental setting (see Figure 11), where $q$ and $P$ have been constructed as the boundary conditions of the tunnel model. Firstly, the axis and horizontal force should be kept constant. Then, the surrounding tunnel wall appears as the prima facie by the tunnel excavation. Lastly, the tensile stress can be found on both sides of the surrounding wall; fracturing will have taken place first in these areas.

The force of decomposition of the "V-shaped" block of rock is shown in Figure 12. In accordance with the effects of force, the formation of "V-shaped" rock burst pits can be broken down into the following three characteristics: Firstly, the effect of the normal stress of $Q_{P}$ is to form a number of tensioning surfaces. Secondly, the effect of the shear stress of $Q_{S}$ is to cut the block out of the mother rock and to put the block out of the surrounding rock. Lastly, under the action of $Q_{P}$ and $Q_{S}$, the area of OAB forms the "V-shaped" rock burst pits.
The calculations for $Q_{S}$ and $Q_{P}$ can be expressed as

$$
\begin{aligned}
& Q_{P}=Q \times \cos \alpha \\
& Q_{S}=Q \times \sin \alpha,
\end{aligned}
$$

where $Q=\sqrt{q^{2}+P^{2}}$.

With the operation of excavation unloading, both the surrounding walls of a tunnel form a "V-shape" rockburst pit; the shear stress of $Q_{S}$ is parallel to the "V-shape" block of rock, and the normal stress of $Q_{P}$ is perpendicular to the " $V$ shape" block of rock. The other stresses are shown in Table 4. We propose that the size of "V-shape" is determined by three parameters, namely, $Q_{P}, Q_{S}$, and $\alpha$ (Figure 12). The size of the "V-shaped" is determined by the magnitude of the destructive force of rockburst occurrence. As described later, there is a positive correlation between the horizontal stress, $Q$, and $Q_{P}$. There is also a positive correlation between the horizontal stress and $Q_{P}, Q_{S}$, and $\alpha$.

Along with the above analysis, the rockburst intensity is positively related to horizontal stress, which means that the greater the horizontal stress, the more serious the rockburst situation. On site, the horizontal stress usually refers to the tectonic stress. If it is observed that this area has high tectonic stress, we should pay more attention to the rockburst occurrence. 


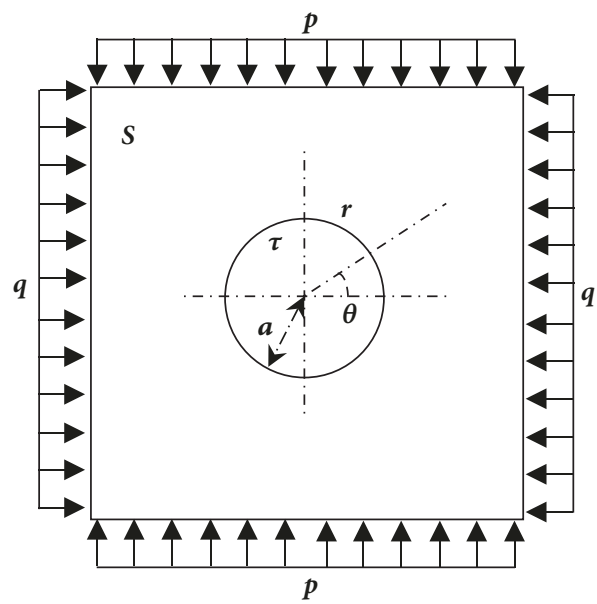

(a) Before

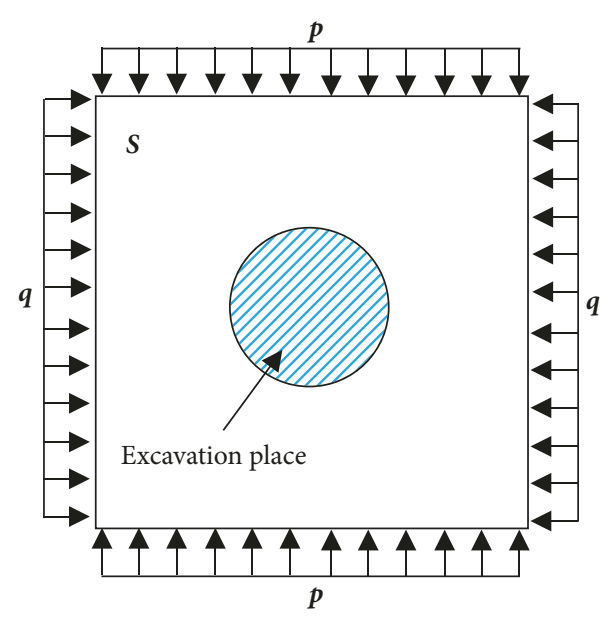

(b) After

FIGURE 11: Stress experienced by the tunnel model before and after excavation.
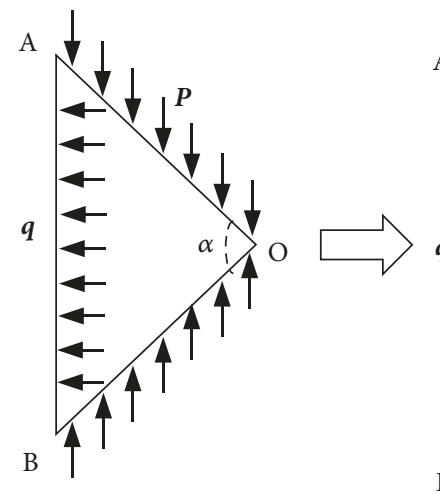
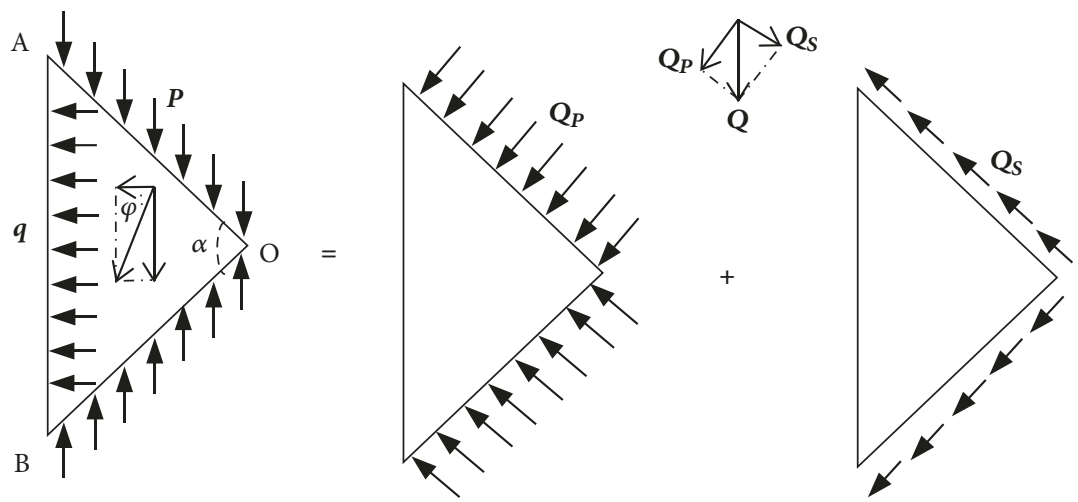

FIGURE 12: Analyzing the stress in the surrounding rock.

5.2. Monitoring Key Areas of Rockburst in Tunnel. The split fracturing caused by the unloading at the left and right sides of a tunnel is the formation mechanism of single rock burst [39]. Essentially, the tunnel enters into the stage of complete ejection and the inner wall of the tunnel produces a rockburst that has the following circulating process: rockburst $\rightarrow$ stress adjustment $\rightarrow$ stress adjustment failure $\rightarrow$ repeated rockburst. While the accumulated energy is released, the process of stress adjustment is over. Finally, a rockburst pit of continuous "V-shape" can be formed on both side walls of the tunnel. For example, by analyzing the advantages and disadvantages of qualitative classification methods for the rockburst intensity at the Jinping II Hydropower Station in Sichuan province, China, we found that the rockburst area along the axis of the hole was either intermittent or continuously distributed. Some rockburst in partial areas lasted for 7-10 days or even up to a month. The experimental conditions are very similar to those encountered at this site.

As can be seen from the above discussion, the middle part of the tunnel first has small particles of popped-up rock, then the rock cuttings begin to eject one after another, and finally the rockburst occurs in the same place. Thus, for this type of rockburst, we should focus on monitoring the space of the middle part of the tunnel.

\section{Conclusion}

In this research, we carried out the simulation test of a rockburst in tunnel, and the process of rockburst evolution was analyzed under different horizontal stresses. In order to capture the characteristics of rockburst in tunnel in various stages (the quiet period stage, the particle ejection stage, the flaking and particle ejection stage, and the complete ejection stage), the mesofracturing mechanical method and AE monitoring were used. We considered the relationship between horizontal stress and the rockburst intensity. The results indicate the following.

(1) The rockburst tendency of granite samples is in Grade II, corresponding to a medium rockburst. The granite samples have a higher elastic modulus and compressive strength, and their capability for withstanding strain is stronger. They are suitable samples for studying the rockburst in tunnel.

(2) According to the stress analysis of the rockburst pits, the horizontal stress and rockburst intensity are positively 
TABLE 4: Mechanical response characteristics of rock blasting process.

\begin{tabular}{|c|c|c|c|c|c|c|c|c|c|}
\hline $\begin{array}{l}\text { Horizontal } \\
\text { stress }(\mathrm{MPa})\end{array}$ & $\begin{array}{c}\text { Vertical stress } \\
(\mathrm{MPa})\end{array}$ & $\begin{array}{c}\text { Average vertical } \\
\text { stress }(\mathrm{MPa})\end{array}$ & $\varphi\left(^{\circ}\right)$ & Average $\varphi\left(^{\circ}\right)$ & $Q(\mathrm{MPa})$ & $\begin{array}{l}\text { Average } \\
Q(\mathrm{MPa})\end{array}$ & $\alpha\left(^{\circ}\right)$ & $Q_{P}(\mathrm{MPa})$ & $Q_{S}(\mathrm{MPa})$ \\
\hline \multirow{4}{*}{4.44} & 100.62 & \multirow{4}{*}{98.80} & 87.47 & \multirow{4}{*}{87.41} & 100.72 & \multirow{4}{*}{98.90} & \multirow{4}{*}{45.94} & \multirow{4}{*}{68.78} & \multirow{4}{*}{72.38} \\
\hline & 86.31 & & 87.05 & & 86.43 & & & & \\
\hline & 101.20 & & 87.48 & & 101.30 & & & & \\
\hline & 107.07 & & 87.62 & & 107.16 & & & & \\
\hline \multirow{4}{*}{8.89} & 107.64 & \multirow{4}{*}{107.71} & 85.28 & \multirow{4}{*}{85.28} & 108.01 & \multirow{4}{*}{108.08} & \multirow{4}{*}{76.42} & \multirow{4}{*}{76.42} & \multirow{4}{*}{45.00} \\
\hline & 109.78 & & 85.37 & & 110.14 & & & & \\
\hline & 111.47 & & 85.44 & & 111.82 & & & & \\
\hline & 101.96 & & 85.02 & & 102.35 & & & & \\
\hline \multirow{4}{*}{13.33} & 108.44 & \multirow{4}{*}{110.79} & 82.99 & \multirow{4}{*}{83.14} & 109.26 & \multirow{4}{*}{111.59} & \multirow{4}{*}{81.41} & \multirow{4}{*}{76.32} & \multirow{4}{*}{43.15} \\
\hline & 109.78 & & 83.07 & & 110.58 & & & & \\
\hline & 111.47 & & 83.18 & & 112.26 & & & & \\
\hline & 101.96 & & 82.55 & & 102.82 & & & & \\
\hline
\end{tabular}

correlated. Thus, the greater the horizontal stress, the higher the impact of the rockburst.

(3) The horizontal stress and fracture type are related. The early stages of rockburst evolution are characterized by a tensile-shear mixed model. Thereafter, the ratio of shear fracturing is positively correlated to the horizontal stress.

(4) In the early stages of a rockburst, the curve of cumulative AE energy shows a "step-like" rising trend. The high intensity and high energy released from the rockfracturing event appear at the rockburst occurrence stage. Thus, we can use this characteristic of a "step-like" rising trend to predict the occurrence of a rockburst in tunnel.

\section{Data Availability}

The data used to support the findings of this study are available from the corresponding author upon request.

\section{Conflicts of Interest}

The authors declare that they have no conflicts of interest.

\section{Acknowledgments}

This work was supported by the National Natural Science Foundation of China (nos. 51604117, 51774138, 51574102, and 51374088) and Hebei Province Natural Science Fund (nos. E2017209241 and E2016209357) which are gratefully acknowledged.

\section{References}

[1] E. Hoek and E. T. Brown, "Practical estimates of rock mass strength," International Journal of Rock Mechanics and Mining Sciences, vol. 34, no. 8, pp. 1165-1186, 1997.

[2] V. Rudajev, J. Vilhelm, and T. Lokajíček, "Laboratory studies of acoustic emission prior to uniaxial compressive rock failure,"
International Journal of Rock Mechanics and Mining Sciences, vol. 37, no. 4, pp. 699-704, 2000.

[3] D. A. Beck and B. H. G. Brady, "Evaluation and application and controlling parameters for seismic events in hard-rock mines," International Journal of Rock Mechanics and Mining Sciences, vol. 39, no. 5, pp. 633-642, 2002.

[4] L. Weng, L. Huang, A. Taheri, and X. Li, "Rockburst characteristics and numerical simulation based on a strain energy density index: A case study of a roadway in Linglong gold mine, China," Tunnelling and Underground Space Technology, vol. 69, pp. 223232, 2017.

[5] K. Y. Lo and C. M. K. Yuen, "Design of tunnel lining in rock for long term time effects," Canadian Geotechnical Journal, vol. 18, no. 1, pp. 24-39, 1981.

[6] Z. Liang, X. Liu, Y. Zhang, and C. Tang, "Analysis of precursors prior to rock burst in granite tunnel using acoustic emission and far infrared monitoring," Mathematical Problems in Engineering, vol. 2013, Article ID 214340, 10 pages, 2013.

[7] C. Tang, J. Wang, and J. Zhang, "Preliminary engineering application of microseismic monitoring technique to rockburst prediction in tunneling of jinping ii project," Journal of Rock Mechanics and Geotechnical Engineering, vol. 2, no. 3, pp. 193-208, 2010.

[8] N. W. Xu, C. A. Tang, L. C. Li et al., "Microseismic monitoring and stability analysis of the left bank slope in Jinping first stage hydropower station in southwestern China," International Journal of Rock Mechanics and Mining Sciences, vol. 48, no. 6, pp. 950-963, 2011.

[9] B. H. Armstrong, "Acoustic emission prior to rockbursts and earthquakes," Bulletin of the Seismological Society of America, vol. 59, no. 3, pp. 1259-1279, 1969.

[10] A. Lavrov, "The Kaiser effect in rocks: principles and stress estimation techniques," International Journal of Rock Mechanics and Mining Sciences, vol. 40, no. 2, pp. 151-171, 2003.

[11] L. R. Li, J. H. Deng, L. Zheng, and J. F. Liu, "Dominant frequency characteristics of acoustic emissions in white marble during direct tensile tests," in Rock Mechanics \& Rock Engineering, pp. 1-10, 2017. 
[12] V. Frid, "Rockburst hazard forecast by electromagnetic radiation excited by rock fracture," Rock Mechanics and Rock Engineering, vol. 30, no. 4, pp. 229-236, 1997.

[13] P. M. Benson, S. Vinciguerra, P. G. Meredith, and R. P. Young, "Laboratory simulation of volcano seismicity," Science, vol. 322, no. 5899, pp. 249-252, 2008.

[14] L.-J. Dong, J. Wesseloo, Y. Potvin, and X.-B. Li, “Discriminant models of blasts and seismic events in mine seismology," International Journal of Rock Mechanics \& Mining Sciences, vol. 86, pp. 282-291, 2016.

[15] L. Dong, J. Wesseloo, Y. Potvin, and X. Li, "Discrimination of mine seismic events and blasts using the fisher classifier, naive bayesian classifier and logistic regression," Rock Mechanics and Rock Engineering, vol. 49, no. 1, pp. 183-211, 2016.

[16] L. Dong, W. Shu, X. Li, G. Han, and W. Zou, “Three Dimensional Comprehensive Analytical Solutions for Locating Sources of Sensor Networks in Unknown Velocity Mining System," IEEE Access, vol. 5, pp. 11337-11351, 2017.

[17] L. Dong, W. Zou, X. Li, W. Shu, and Z. Wang, "Collaborative localization method using analytical and iterative solutions for microseismic/acoustic emission sources in the rockmass structure for underground mining," Engineering Fracture Mechanics, 2018.

[18] T. Ishida, T. Kanagawa, and Y. Kanaori, "Source distribution of acoustic emissions during an in-situ direct shear test: implications for an analog model of seismogenic faulting in an inhomogeneous rock mass," Engineering Geology, vol. 110, no. 3-4, pp. 66-76, 2010.

[19] G. Chen, T. Li, G. Zhang, H. Yin, and H. Zhang, “Temperature effect of rock burst for hard rock in deep-buried tunnel," Natural Hazards, vol. 72, no. 2, pp. 915-926, 2014.

[20] M.-C. He, J.-L. Miao, and J.-L. Feng, "Rock burst process of limestone and its acoustic emission characteristics under truetriaxial unloading conditions," International Journal of Rock Mechanics and Mining Sciences, vol. 47, no. 2, pp. 286-298, 2010.

[21] M. C. He, F. Zhao, M. Cai, and S. Du, "A Novel Experimental Technique to Simulate Pillar Burst in Laboratory," Rock Mechanics and Rock Engineering, vol. 48, no. 5, pp. 1833-1848, 2015.

[22] F. Zhao and M. C. He, "Size effects on granite behavior under unloading rockburst test," Bulletin of Engineering Geology the Environment, pp. 1-15, 2016.

[23] M. Cai and P. K. Kaiser, "Assessment of excavation damaged zone using a micromechanics mode," Tunnelling \& Underground Space Technology Incorporating Trenchless Technology Research, vol. 20, no. 4, pp. 301-310, 2005.

[24] N. Dixon and M. Spriggs, "Quantification of slope displacement rates using acoustic emission monitoring," Canadian Geotechnical Journal, vol. 44, no. 8, pp. 966-976, 2007.

[25] D. Arosio, L. Longoni, M. Papini, M. Scaioni, L. Zanzi, and M. Alba, "Towards rockfall forecasting through observing deformations and listening to microseismic emissions," Natural Hazards and Earth System Sciences, vol. 9, no. 4, pp. 1119-1131, 2009.

[26] G. Cheng, T. Ma, C. Tang, H. Liu, and S. Wang, "A zoning model for coal mining - induced strata movement based on microseismic monitoring," International Journal of Rock Mechanics and Mining Sciences, vol. 94, pp. 123-138, 2017.

[27] A. Farhidzadeh, A. C. Mpalaskas, T. E. Matikas, H. Farhidzadeh, and D. G. Aggelis, "Fracture mode identification in cementitious materials using supervised pattern recognition of acoustic emission features," Construction and Building Materials, vol. 67, pp. 129-138, 2014.
[28] T. Ishida, J. F. Labuz, G. Manthei et al., "ISRM Suggested Method for Laboratory Acoustic Emission Monitoring," Rock Mechanics and Rock Engineering, vol. 50, no. 3, pp. 665-674, 2017.

[29] H. N. Wang, S. Utili, M. J. Jiang, and P. He, "Analytical Solutions for Tunnels of Elliptical Cross-Section in Rheological Rock Accounting for Sequential Excavation," Rock Mechanics and Rock Engineering, vol. 48, no. 5, pp. 1997-2029, 2015.

[30] G. Graham, S. Crampin, and L. M. Fernandez, "Observations of shear-wave polarizations from rockbursts in a South African gold field: an analysis of acceleration and velocity recordings," Geophysical Journal International, vol. 107, no. 3, pp. 661-672, 1991.

[31] J. Xu, J. Jiang, N. Xu, Q. Liu, and Y. Gao, "A new energy index for evaluating the tendency of rockburst and its engineering application," Engineering Geology, vol. 230, pp. 46-54, 2017.

[32] A. Kusui, E. Villaescusa, and T. Funatsu, "Mechanical behaviour of scaled-down unsupported tunnel walls in hard rock under high stress," Tunnelling and Underground Space Technology, vol. 60, pp. 30-40, 2016.

[33] H. Zhou, F. Meng, C. Zhang, D. Hu, F. Yang, and J. Lu, "Analysis of rockburst mechanisms induced by structural planes in deep tunnels," Bulletin of Engineering Geology and the Environment, vol. 74, no. 4, pp. 1435-1451, 2015.

[34] N. D’Agostino, D. Cheloni, S. Mantenuto, G. Selvaggi, A. Michelini, and D. Zuliani, "Strain accumulation in the southern Alps (NE Italy) and deformation at the northeastern boundary of Adria observed by CGPS measurements," Geophysical Research Letters, vol. 32, no. 19, Article ID L19306, pp. 477-485, 2005.

[35] J. Yang, W. Lu, M. Chen, P. Yan, and C. Zhou, "Mechanism and identification of triggered microseism by transient release of insitu stress in deep rock mass," Earthquake Science, vol. 34, no. 5, pp. 581-592, 2012.

[36] X.-P. Zhou and Y.-D. Shou, "Excavation-induced zonal disintegration of the surrounding rock around a deep circular tunnel considering unloading effect," International Journal of Rock Mechanics and Mining Sciences, vol. 64, pp. 246-257, 2013.

[37] M. Ohtsu, Y. Tomoda, and T. Suzuki, "Damage evaluation and corrosion detection in concrete by acoustic emission," in Fracture mechanics of concrete and concrete structure-design. Assessment and retrofitting of $R C$ structures, Carpinteri et al., Ed., Taylor and Francis Group, London, UK, 2007.

[38] T. Shiotani, "Parameter analysis," in Acoustic Emission Testing, C. Grosse and M. Ohtsu, Eds., pp. 41-51, Springer, Berlin, Germany, 2008.

[39] L. Xiangxin, L. Zhengzhao, Z. Yanbo, Y. Xulong, and L. Haiyang, "Unloading test for rockburst mechanism in tunnel model," Journal of Engineering Geology, vol. 24, no. 5, pp. 967-975, 2016. 


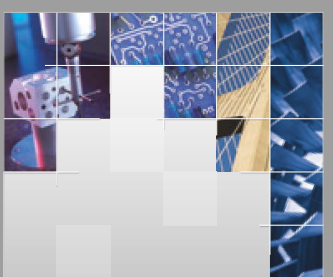

\section{Enfincering}
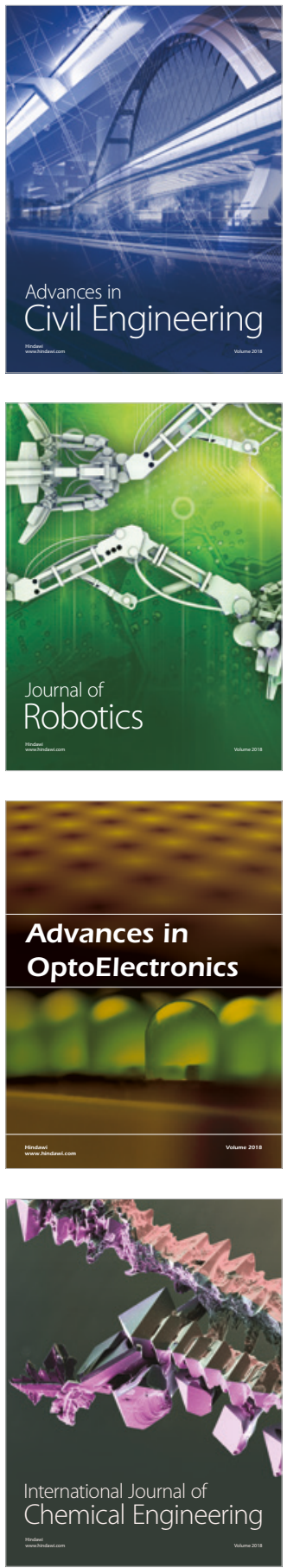

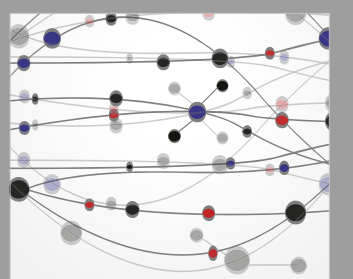

\section{Rotating \\ Machinery}

The Scientific World Journal

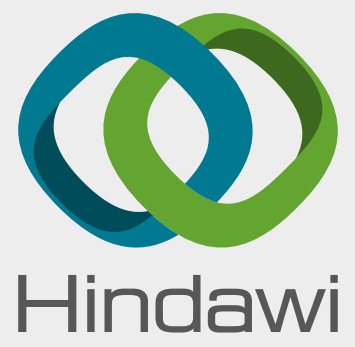

Submit your manuscripts at

www.hindawi.com
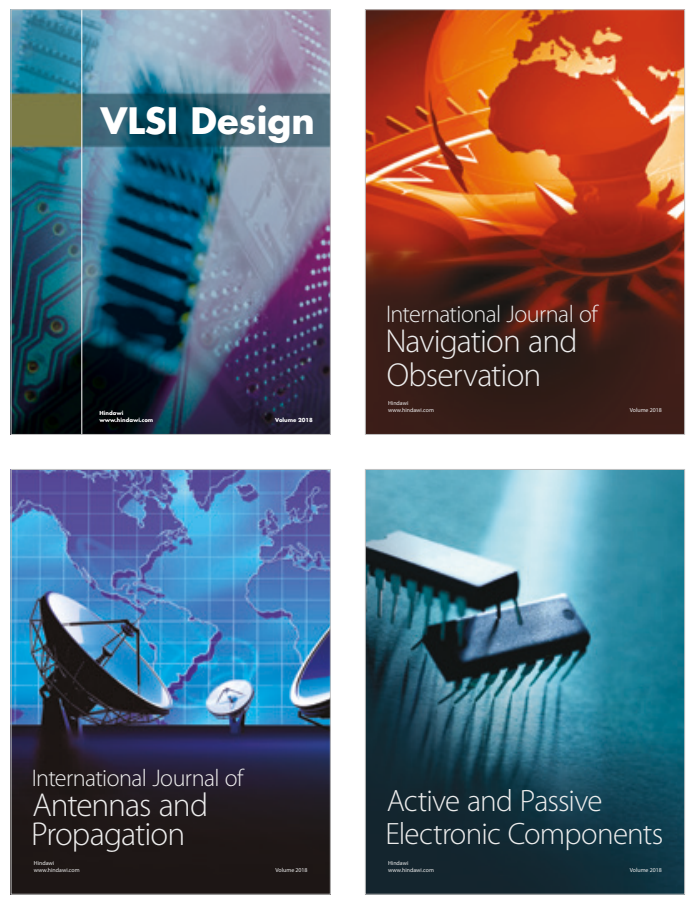
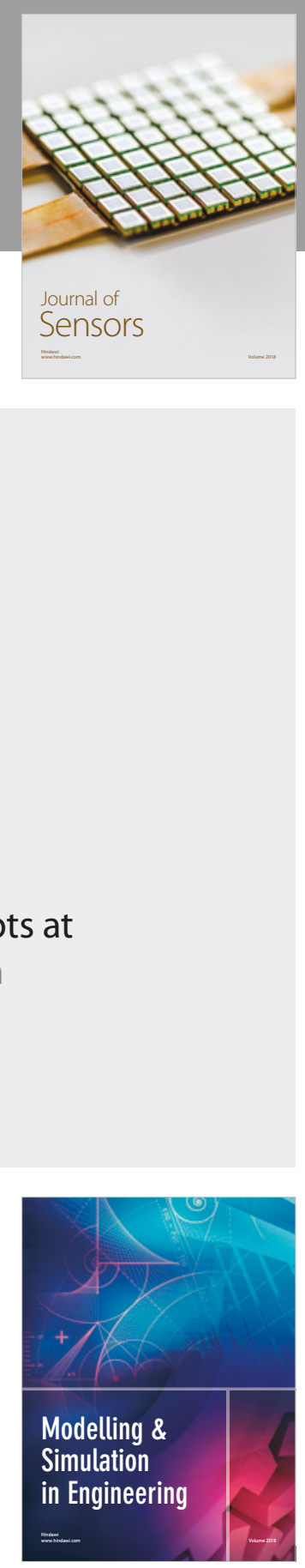

\section{Advances \\ Multimedia}
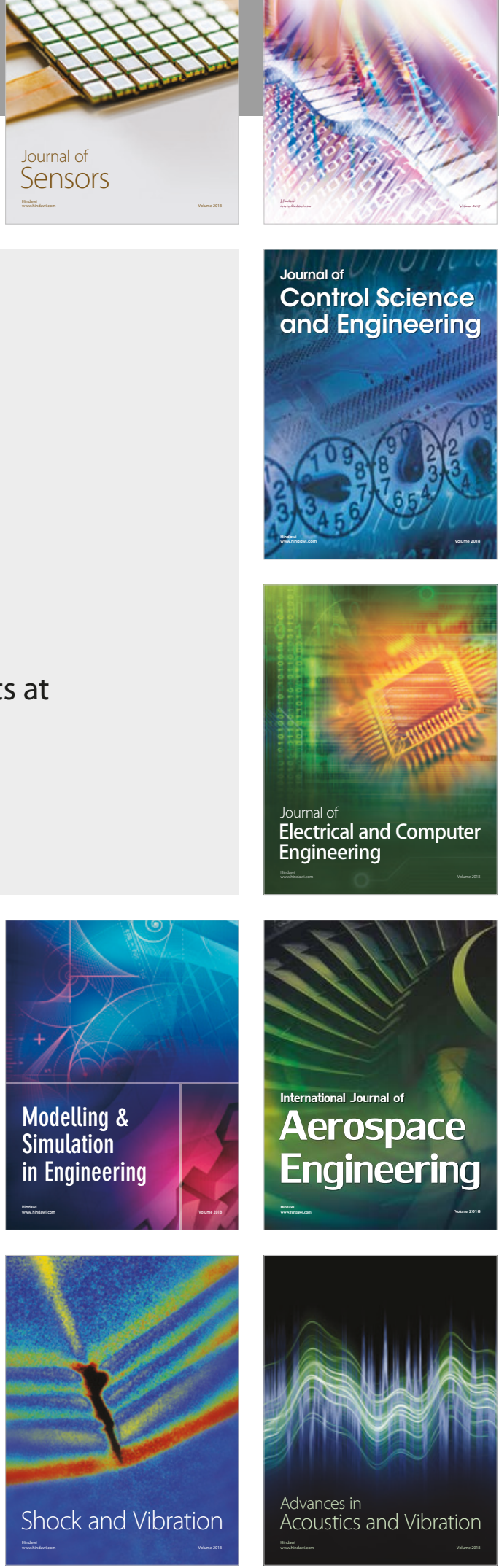